Rev. Bras. Saúde Prod. Anim., Salvador, v.16, n.3, p.746-757 jul./set.., $2015 \quad \underline{\text { http://www.rbspa.ufba.br }}$

\title{
Início da puberdade de cordeiros provenientes de ovelhas deslanadas submetidas à restrição calórica ou proteica
}

\section{Puberty beginning in lambs from hairless ewe submitted to caloric or protein restriction}

\author{
FRAGA, Ana Laísa Cândida de Resende ${ }^{1 *}$; HATAMOTO-ZERVOUDAKIS, Luciana \\ Keiko $^{2}$; SILVA JÚNIOR, Lourival de Souza ; CABRAL, Luciano da Silva²; SOUZA, \\ José Ricardo de ${ }^{2}$; BARROS, Danillo Salgado ${ }^{1}$; ANGREVES, Giselde Marques ${ }^{1}$
}

\author{
${ }^{1}$ Universidade Federal de Mato Grosso, Programa de Pós-Graduação em Ciência Animal, Cuiabá, Mato \\ Grosso, Brasil. \\ ${ }^{2}$ Universidade Federal de Mato Grosso, Faculdade de Medicina Veterinária e Zootecnia,Cuiabá, Mato \\ Grosso, Brasil. \\ *Endereço para correspondência: analaisa.fraga@hotmail.com
}

\section{RESUMO}

O estudo foi realizado para avaliar se a restrição calórica ou proteica em fêmeas lactantes influencia o início da puberdade de seus cordeiros. Foram utilizados 21 cordeiros, sendo duas fêmeas e cinco machos por tratamento. Durante sessenta dias as mães receberam o tratamento aleatoriamente escolhido para o seu cordeiro: controle ( $\mathrm{TC}$, mantença), restrição calórica (TRC, 1/2 da energia do TC) e restrição proteica (TRP, 1/3 da proteína do TC). Após o desmame, os cordeiros receberam uma dieta composta por silagem de milho e concentrado, sendo pesados e avaliados quinzenalmente. Nos machos, coletava-se o ejaculado, mensurava-se circunferência escrotal e as dimensões testiculares. Nas fềmeas, realizava-se ultrassonografia para medir os ovários e verificar presença de corpo lúteo. Os machos eram considerados púberes se apresentassem ejaculado com, no mínimo: motilidade de $50 \%$, concentração do ejaculado de $50 \times 10^{6}$ espermatozóides $/ \mathrm{mL}$ e, no máximo, $50 \%$ de anormalidades espermáticas totais, e as fêmeas, se apresentassem corpo lúteo. Foi encontrada interação entre período de avaliação e tratamento para circunferência escrotal $(p=0,0019)$, volume testicular médio $(\mathrm{p}=0,0025)$, motilidade $(p<0,0001)$ e concentração espermática $(p=0,027)$, sendo o TRP, mais tardio do que TRC e TC em todas variáveis. Nas borregas não houve diferença $(p>0,05)$ entre os tratamentos quanto às características foliculares, porém houve quanto ao corpo lúteo $(p=0,0179)$. Notou-se que as fêmeas do TC apresentaram corpo lúteo a partir da $10^{\mathrm{a}}$ semana, TRC da $11^{\mathrm{a}}$ e o TRP da $13^{\mathrm{a}}$. Concluiu-se que a restrição proteica materna durante a lactação atrasa o início da puberdade de seus cordeiros.

Palavras-chaves: corpo lúteo, reprodução, sêmen, subnutrição

\section{SUMMARY}

This study was carried out to evaluate if caloric or protein restriction in lactation ewe affect puberty beginning of its lambs. Had been used 21 lambs, two females and five males per type of treatment. During 60 days the mothers received the treatment for which its lamb was sort out: Control Treatment (TC, maintenance), Energy Restriction Treatment (TRC, $1 / 2$ of the energy of the TC) and Protein Restriction Treatment (TRP, 1/3 of the protein of the TC). The lambs were weaned and received a diet composed by corn silage and concentrate, weighed and evaluated fortnightly. In males, the ejaculate was collected, scrotal circumference and testicular size measured. In females, it was realized ultrasound to measure the ovaries and verify the corpus luteum presence. For males was considered in puberty if produced ejaculation with at least: motility of $50 \%$, sperm concentration of $50 \times 10^{6}$ espermatozoa $/ \mathrm{mL}$ and maximum of $50 \%$ total sperm abnormalities, and females if exhibit corpus luteum. An interaction was found between evaluation period and treatment for scrotum circumference 
$(\mathrm{p}=0.0019)$, testicular volume $(\mathrm{p}=0.0025)$ sperm motility $(p<0.0001)$ and concentration $(p=0.027)$, TRP was later than TRC and TC in all variable. In female no treatment effect $(\mathrm{p}>0.05)$ were found about follicles characteristics, however that was difference in the presence of corpous luteum $(p=0.0179)$. The TC females showed corpus luteum from the $10^{\text {th }}$ week, TRC $11^{\text {th }}$ and $13^{\text {th }}$ for TRP. It was concluded that mother protein restriction during the lactation delays the beginning of the puberty of its lambs.

Keywords: corpus luteum, reproduction, semen, subnutrition

\section{INTRODUÇÃO}

A produtividade de um rebanho depende do sucesso de alguns aspectos reprodutivos, como: taxa de natalidade, detecção de estro, estacionalidade reprodutiva e idade à puberdade (LOBATO et al., 2013). A idade à puberdade é um fator genético e determinante sobre capacidade reprodutiva, podendo ser influenciada por fatores externos, como a temperatura, umidade do ar e o fotoperíodo (MAIA et al., 2011). Mas a nutrição é considerada o fator principal para o estabelecimento da puberdade, devido à complexa interação dos diversos nutrientes com os processos reprodutivos, afetando, ainda, a eficiência reprodutiva das futuras fases da vida do animal (PIRES, 2011; ROBINSON et al., 2006).

A seleção de machos ovinos para utilização como reprodutores é uma excelente ferramenta para maximizar a produtividade do rebanho, devendo ser avaliada a qualidade seminal, as características testiculares e o comportamento reprodutivo (PACHECO \& QUIRINO, 2010).

Segundo Hulet \& Shelton (2004), os machos podem apresentar libido com a proximidade da puberdade, entretanto, ela somente será estabelecida quando os espermatozóides encontrarem-se viáveis para fecundação, atingindo a maturidade sexual com cerca de seis meses de idade, com peso vivo de $40-60 \%$ do peso adulto. Já as fêmeas, nascem com sua população folicular pré-formada, porém alcançam a maturidade sexual em torno dos cinco meses de idade e o primeiro cio pode aparecer quando atingirem de 30 a $50 \mathrm{Kg}$ (HULET \& SHELTON, 2004).

$\mathrm{O}$ aumento da oferta de alimento à ovelha no pós-parto pode influenciar de forma positiva o crescimento e diminuir a idade à puberdade de seu cordeiro (CARDOSO \& NOGUEIRA, 2007). Já a subnutrição no início da vida dos cordeiros provoca queda do desempenho reprodutivo futuro de forma vitalícia, independente da nutrição durante a vida adulta (ROBINSON et al., 2006).

Devido às poucas informações a respeito da restrição nutricional em ovinos e sua interação com o início da puberdade, este estudo foi realizado com o objetivo de verificar se o início da puberdade dos cordeiros é influenciado pela restrição calórica ou proteica das mães durante o período de amamentação.

\section{MATERIAL E MÉTODOS}

O trabalho foi realizado no setor de ovinocultura da fazenda experimental da Universidade Federal de Mato Grosso (UFMT), localizada em Santo Antônio do Leverger, município distante $30 \mathrm{Km}$ de Cuiabá, durante o período de um ano, de outubro a outubro. O município de Santo Antônio do Leverger encontra-se na altitude de $141 \mathrm{~m}$, latitude $15^{\circ} 51^{\prime} 56^{\prime \prime}$ sul e longitude $56^{\circ} 04^{\prime} 36^{\prime \prime}$ oeste. O clima da região, segundo a classificação de Koppen, é tropical, megatérmico, com duas estações bem definidas, verão chuvoso (outubro a março) e inverno seco (abril a setembro). A temperatura 
média anual é $24^{\circ} \mathrm{C}$, e a pluviosidade média anual, de $1300 \mathrm{~mm}$.

No experimento, foram utilizadas 21 ovelhas deslanadas, sem raça definida, paridas no mês de novembro, e seus respectivos cordeiros. As ovelhas, juntamente com suas crias, foram divididas aleatoriamente em três grupos logo após o parto. No total, utilizou-se 21 cordeiros, sendo seis fêmeas e 15 machos (duas fêmeas e cinco machos para cada grupo experimental). Os cordeiros foram desmamados com 60 dias de idade e, durante a lactação, as ovelhas foram submetidas aos tratamentos experimentais. Os animais foram mantidos em piquetes dotados de comedouro, bebedouro, cocho de sal mineral e solarium.

A dieta oferecida às ovelhas do tratamento controle (TC) supria os requerimentos de mantença e lactação (NRC, 1985), sendo composta por silagem de milho, cana-de-açúcar e ração concentrada, e o consumo, baseado em $4,5 \%$ de peso vivo de matéria seca por animal (PV/MS/animal/dia). Para as ovelhas do tratamento com restrição calórica (TRC), era fornecida uma dieta que supria metade dos requerimentos de mantença do $\mathrm{TC}$, enquanto que, para o tratamento de restrição proteica (TRP), a dieta fornecia um terço (1/3) dos requerimentos proteicos de mantença do TC. A oferta de alimento da dieta por quilo de matéria seca ( $\mathrm{kg}$ de MS) dos tratamentos TC, TRC e TRP eram 1,94; 0,97 e 1,59, respectivamente. Já a energia metabolizável por ovelha e por $\mathrm{Kg}$ de MS dos tratamentos foram 4,94 e 2,55 no TC, 2,46 e 2,55 no TRC e 3,55 e 2,23 no TRP, respectivamente.

Foi realizado ajuste na oferta de alimento na ordem de $6 \% \mathrm{PV} / \mathrm{MS} /$ animal/dia em torno dos 30 dias da lactação, de acordo com o aumento da demanda de energia metabólica do período (NRC,1985). E, com o reajuste, a oferta de alimento da dieta ( $\mathrm{kg}$ de MS) dos tratamento TC, TRC e TRP passaram para 2,71, 1,35 e 1,41, respectivamente. A energia metabolizável por ovelha e por quilo de matéria seca dos tratamentos também foram alteradas para 6,86 e 2,53 no $\mathrm{TC}, 3,44$ e 2,54 no TRC e 3,34 e 2,37 no TRP. O período de arroçoamento com as dietas experimentais foi de 60 dias, sendo fornecido em dois períodos por dia (manhã e tarde), com água e sal mineral ad libitum.

Com 60 dias de lactação, os cordeiros foram desmamados e passaram a receber uma dieta a base de silagem de milho e concentrado durante 20 dias, para adaptação. Depois desse período, foi formulada outra dieta para atender a exigência nutricional de cordeiros na fase de desenvolvimento (NRC, 1985; Tabela 1), a partir da média de peso corporal por grupo. Essa dieta era constituída de silagem de milho e concentrado - farelo de milho (66\%), farelo de soja $(28 \%)$, matéria mineral $(5 \%)$ e ureia $(1 \%)$. O arraçoamento dos borregos foi fornecido em dois períodos (manhã e tarde) e a água e sal mineral eram ad libitum.

Os animais foram avaliados após o desmame quinzenalmente até se tornarem púberes. Na avaliação, era realizada a pesagem de cada animal e a observação de determinadas características sexuais. Para os machos, a entrada na puberdade foi definida quando o animal produzisse um ejaculado com as seguintes características: motilidade espermática maior ou igual a $50 \%$, concentração espermática mínima de $50 \mathrm{x}$ $10^{6}$ espermatozóides $/ \mathrm{mL}\left(10^{6} \mathrm{SPTZ} / \mathrm{mL}\right)$ (MÉNDEZ et al., 2005) e um máximo de $50 \%$ de anormalidades espermáticas (AVELLANEDA et al., 2006).

Foram avaliadas a circunferência escrotal (CE) e as dimensões testiculares (comprimento, largura, espessura), conforme procedimento descrito por 
Jacomini et al. (2007). As colheitas de sêmen foram realizadas utilizando-se eletroestimulação e o ejaculado colhido em tubo graduado, isolado de choque térmico e luz. O início da colheita se deu logo após o desmame (60 dias de idade) e as avaliações seminais foram realizadas a partir do momento em que se encontraram espermatozoides vivos nas amostras de sêmen colhidas.

Tabela 1. Peso vivo médio e quantidade de silagem, concentrado, matéria seca e energia metabolizável fornecida aos borregos após o período de lactação em função dos tratamentos controle (TC), restrição calórica (TRC) e restrição proteica (TRP)

\begin{tabular}{lccc}
\hline Descrição & TC & TRC & TRP \\
\hline Média de Peso Vivo (Kg) & 24,00 & 16,30 & 13,30 \\
Silagem/borrego/dia (Kg de MS ${ }^{1}$ ) & 0,42 & 0,30 & 0,32 \\
Concentrado/borrego/dia (Kg de $\mathrm{MS}^{1}$ ) & 0,32 & 0,30 & 0,27 \\
${ }^{1} \mathrm{MS}$ ofertada/borrego/dia (Kg) & 0,77 & 0,61 & 0,59 \\
${ }^{2} \mathrm{EM}(\mathrm{Mcal} /$ borrego/dia) & 2,00 & 1,60 & 1,64 \\
${ }^{2} \mathrm{EM}\left(\mathrm{Mcal} / \mathrm{Kg}\right.$ de $\mathrm{MS}^{1}$ da dieta) & 2,60 & 2,62 & 2,61 \\
\hline
\end{tabular}

${ }^{\mathrm{T}} \mathrm{MS}=$ matéria seca; ${ }^{2} \mathrm{EM}=$ energia metabolizável.

As características seminais avaliadas no momento da coleta foram o volume e aspecto do ejaculado, motilidade, vigor e turbilhonamento espermáticos (CBRA, 1998). Imediatamente após a colheita, foram retiradas amostras para avaliação da morfologia e concentração espermáticas, colorações de eosinanigrosina (CBRA, 1998) e acrossomal simples (POPE et al., 1991) e realização do teste de expansão hipo-osmótico (BACINOGLU et al., 2008). A análise das amostras foi realizada no laboratório de biotecnologia e reprodução animal (LABRA) da Faculdade de agronomia e medicina veterinária, localizado na Universidade Federal de Mato Grosso, em Cuiabá.

Já as fêmeas, foram avaliadas, para determinação do início da puberdade, através de ultrassonografia via transretal (Pie Medical, modelo Scanner 100LC), com probe linear frequência de $8 \mathrm{MHz}$. A presença de corpo lúteo foi considerada como indicativo do início da atividade cíclica ovariana e, com isso, a puberdade (KINDER et al., 1987). Foram mensurados, em cada ovário (esquerdo e direito): a largura e o comprimento maior, o número e diâmetro dos folículos existentes e o diâmetro do corpo lúteo. $\mathrm{O}$ volume ovariano foi calculado conforme a metodologia descrita por Sartori et al., (2002).

O experimento foi inteiramente casualizado, com medidas repetidas no tempo, e as analises foram realizadas através do aplicativo SAS $^{\circledR} \quad$ (SAS, 2001). O efeito de tratamento e colheita foi avaliado através da ANOVA e os tratamentos foram comparados entre si, através de teste Duncan, com nível de significância de 5\%. Foi calculada a correlação simples de Pearson entre as variáveis.

\section{RESULTADOS E DISCUSSÃO}

Observou-se efeito de tratamento sobre o peso dos borregos ao desmame $(\mathrm{p}=0,0001)$ : os tratamentos TRC $(34,68$ $\pm 12,59)$ e $\operatorname{TRP}(33,15 \pm 13,08)$ não 
diferiram entre si, porém foram inferiores ao TC $(42,96 \pm 16,24)$. Estes resultados indicam que as restrições calórica e proteica aplicadas às mães durante o período de lactação afetou o peso de seus cordeiros. Esses achados foram semelhantes aos de Mancio et al. (2005), que encontraram diferença no peso dos cordeiros da raça "merino australiano", submetidos a quatro diferentes níveis nutricionais (baixo baixo, baixo - alto, alto - alto e alto baixo), com base na oferta de MS, durante os períodos pré e pós-parto. Os cordeiros dos grupos com baixa disponibilidade de MS durante a lactação desmamaram mais leves do que os do grupo com alta disponibilidade de MS $(25,8 \pm 4,3$ vs $28,0 \pm 4,2)$.

A circunferência escrotal (Figura 1) e o volume testicular médio (Figura 2) apresentaram interação entre tratamento e número de colheita $(p<0,0001)$. Da primeira à terceira colheita, não houve diferenças entre TRC e TRP, mas o TRC não diferenciou, também, de TC, sendo este superior ao TRP. Entretanto, nas colheitas quatro, cinco e seis não se observou diferença entre o TRC e TC, sendo, ambos, superiores ao TRP. Talvez o valor encontrado a partir da sétima semana do grupo TC pode ter sido influenciado pela saída de dois animais do experimento. Até doze semanas pósdesmame, podemos observar efeito da nutrição no desenvolvimento testicular, sendo mais severa nos animais com restrição proteica. Já após a sexta colheita, não foi verificada diferença entre os tratamentos TRC, TRP e TC, pois a dieta pós-desmame foi a mesma para todos os animais experimentais, promovendo a recuperação dos animais dos grupos com restrição.

Mancio et al. (2005), apesar de não observarem o efeito das diferentes dietas em relação à circunferência escrotal, destacaram que os grupos (baixo - baixo, baixo - alto, alto - alto e alto - baixo, pré e pós-natal, respectivamente) tenderam a responder mais prontamente às mudanças da dieta para o aumento do perímetro escrotal, indicando que a nutrição atuou como fator limitante para o crescimento testicular. Os autores afirmaram que, para animais em crescimento, um inadequado suprimento de nutrientes reduz a divisão celular dos tecidos e dos órgãos.

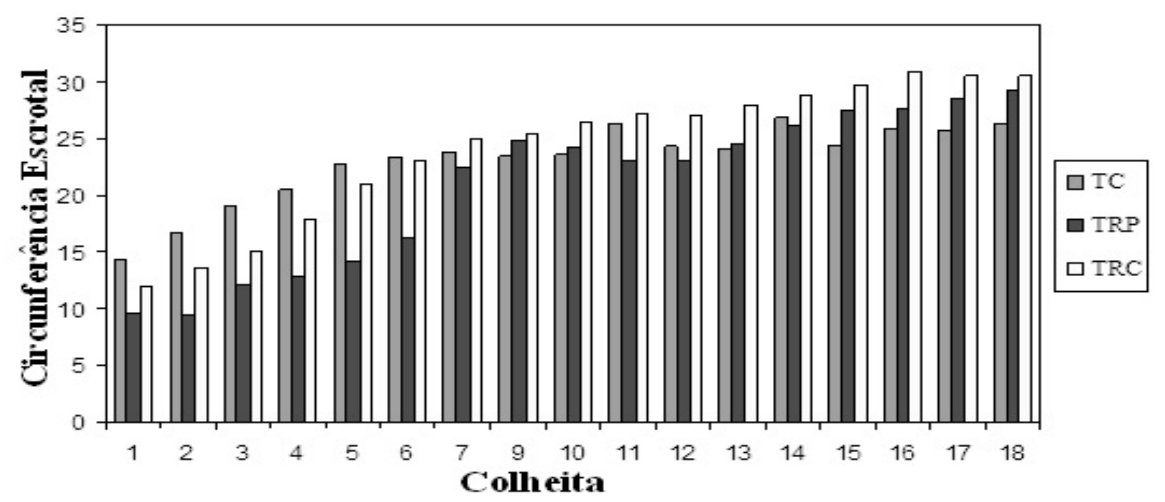

Figura 1. Circunferência escrotal $(\mathrm{cm})$ de cordeiros dos tratamentos experimentais: tratamento controle $(\mathrm{TC}-$ dieta de mantença), restrição energética (TRC $-1 / 2$ da energia do TC) e proteica (TRP - 1/3 da proteína do TC) 
Rev. Bras. Saúde Prod. Anim., Salvador, v.16, n.3, p.746-757 jul./set.., $2015 \quad \underline{\text { http://www.rbspa.ufba.br }}$

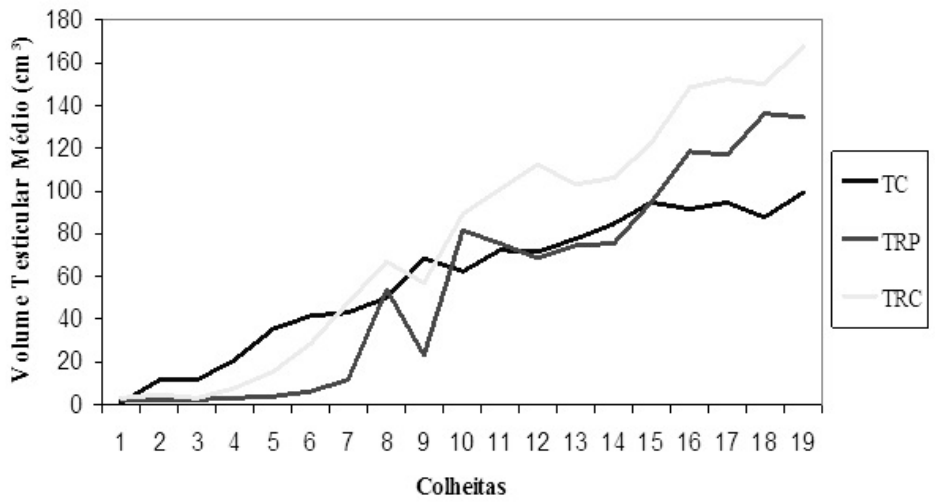

Figura 2. Volume testicular $\left(\mathrm{cm}^{3}\right)$ dos tratamentos TC, TRC e TRP de cordeiros filhos de mães submetidas ao tratamento controle (TC), restrição energética (TRC) e proteica (TRP) durante a lactação

Foi encontrada uma correlação positiva entre o peso e a circunferência escrotal $(\mathrm{r}=0,78422, \mathrm{p}<0,0001)$, sendo mais alta que a correlação encontrada por Aguiar et al. (2008) $(\mathrm{r}=0,28, \quad \mathrm{p}<0,001)$ e se aproximando dos valores observados por Martins et al. (2003), que obteve uma correlação alta e positiva $(\mathrm{r}=0,87$, $\mathrm{p}<0,01)$ entre o peso e as características testiculares, indicando maior desenvolvimento testicular nos animais mais pesados em relação aos mais leves. $\mathrm{O}$ volume testicular (Figura 2) apresentou uma correlação positiva com a circunferência escrotal $(\mathrm{r}=0,9792$, $p<0,0001)$, peso $(r=0,7909, p<0,0001)$, presença de espermatozoide $(\mathrm{r}=0,7760$, $\mathrm{p}<0,0001)$, motilidade espermática ( $\mathrm{r}=$ $0,7247, p<0,0001)$ e vigor espermático $(r$ $=0,6978, \mathrm{p}<0,0001)$, porém, conforme passadas as colheitas, os grupos com restrições nutricionais demonstram compensação do volume testicular, assim como ocorreu com a circunferência testicular. A partir dos resultados encontrados, pode ser observado que a restrição calórica ou proteica das mães durante a amamentação de seus cordeiros promoveu um atraso no desenvolvimento testicular.

Quanto ao turbilhonamento espermático (Figura 3), houve interação entre o tratamento e o momento de colheita ( $\mathrm{p}=0,0095)$, sendo que, no $\mathrm{TC}$, o inicio da produção espermática foi observado na quinta colheita $(0,20 \pm 0,44)$, com idade média de 143,43 $\pm 11,18$ dias. $\mathrm{Na}$ sétima colheita ocorreu o inicio da produção espermática do TRC (idade média de 157,00 \pm 7,32 dias), não sendo observado turbilhonamento nesta colheita. Na nona colheita, o TRP (idade média de 195,83 \pm 8,59 dias) apresentou início da produção espermática, mas ainda sem a presença de turbilhonamento, enquanto que $\mathrm{o}$ TC e o TRC já apresentavam $(1,0 \pm 1,73$ e $0,7 \pm 0,57$, respectivamente $-\mathrm{P}>0,05)$. $\mathrm{O}$ TRP só apresentou turbilhonamento espermático na $11^{\text {a }}$ colheita $(0,66 \pm 1,15)$, não diferindo de TC $(1,3 \pm 2,3)$ e TRC $(1,3 \pm$ 1,3). Esses dados demonstram que a restrição proteica afetou negativamente a qualidade do ejaculado, traduzida pela ausência de turbilhonamento, pois tal parâmetro é resultante da interação entre a motilidade, vigor e concentração espermática. A partir da $11^{\mathrm{a}}$ colheita, pode ser observado o efeito de compensação sobre as restrições nutricionais, já que os grupos não diferiram mais. 
Rev. Bras. Saúde Prod. Anim., Salvador, v.16, n.3, p.746-757 jul./set.., $2015 \quad \underline{\text { http://www.rbspa.ufba.br }}$ ISSN 15199940

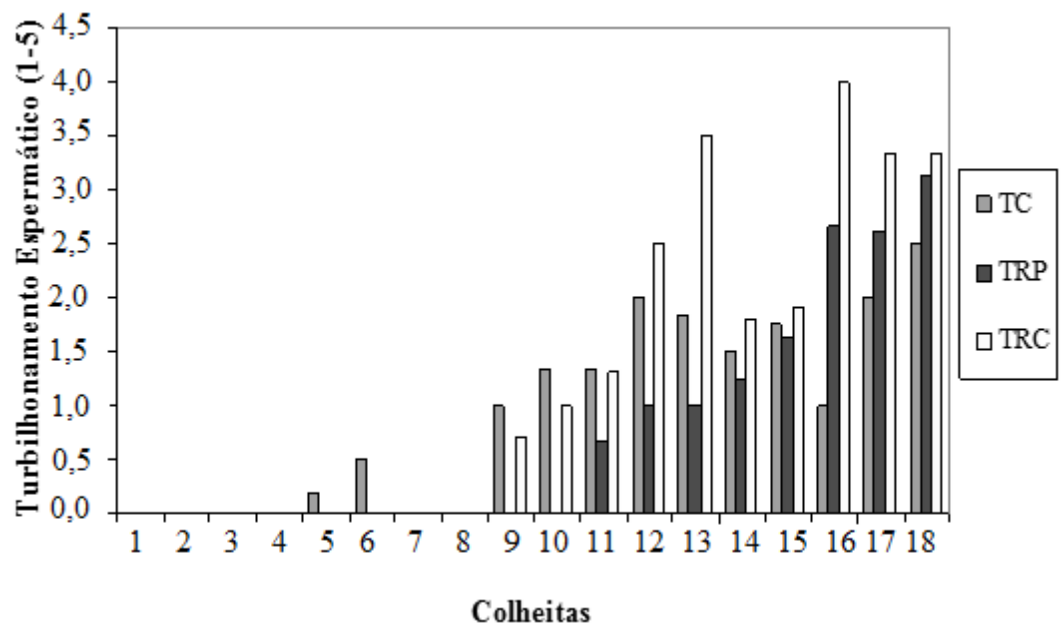

Figura 3. Turbilhonamento do ejaculado (1-5) de cordeiros filhos de mães submetidas ao tratamento controle (TC), restrição energética (TRC) e proteica (TRP), durante a lactação

O efeito da interação tratamento e ordem de colheita foi observado na variável motilidade espermática $(\mathrm{p}<0,0001$; Figura 4). O TC produziu um ejaculado com motilidade a partir da colheita quatro, com quatro meses de idade $(1,00 \% \pm 2,24)$, entretanto, somente alcançou o valor de $50 \%$ de motilidade na $12^{\mathrm{a}}$ colheita $(65,00 \% \pm$ $39,05)$, com idade de 236,43 $\pm 11,18$ dias. Nesta colheita, não se observou diferença entre TRC e TC, apesar do TRC ter produzido um ejaculado com motilidade somente após a nona colheita $(29,00 \% \pm 22,47)$ e, já na $12^{\mathrm{a}}$ colheita, ter apresentado uma motilidade superior a $50 \%(63,00 \% \pm$ 26,36), com idade de $230 \pm 7,32$ dias. O TRP apresentou um comportamento diferente, pois somente na $11^{\mathrm{a}}$ colheita foi obtido o primeiro ejaculado com motilidade $(26,67 \% \pm 25,16)$ e só na $13^{\mathrm{a}}$ colheita, $251,83 \pm 8,59$ dias, foi que os animais alcançaram a motilidade mínima estipulada $(56,67 \% \pm 33,29)$. Corrêa et al. (2006) avaliaram a influência de três diferentes regimes alimentares (a pasto, a pasto com suplementação de $2 \mathrm{Kg} / \mathrm{animal} / \mathrm{dia}$ de concentrado e estabulados - começando com $2 \mathrm{Kg} /$ animal/dia de concentrado até atingirem $6 \mathrm{Kg} /$ animal/dia) sobre as características seminais de bovinos da raça tabapuã com um ano de idade. Esses autores não observaram diferença quanto à motilidade espermática de animais criados a pasto com e sem suplementação $\quad(20,27 \%$ e $14,17 \%$, respectivamente), porém houve diferença $(\mathrm{P}<0,05)$ entre grupos criados à pasto com o grupo estabulado (42,00\%), demonstrando o importante papel da nutrição sobre este parâmetro seminal.

$\mathrm{O}$ vigor espermático (Figura 5) apresentou interação entre tratamento e ordem de colheita $(\mathrm{p}<0,0001)$; os tratamentos TC, TRC e TRP produziram o primeiro ejaculado com vigor espermático na quarta, nona e $11^{\mathrm{a}}$, colheitas com as idades de 118,43 \pm $11,19,189,00 \pm 7,32$ e $222,83 \pm 8,59$ dias, respectivamente, demonstrando efeito da restrição nutricional sobre o vigor espermático, sendo que os animais do TRP demoraram mais tempo para produzirem um ejaculado com essa característica. 
Rev. Bras. Saúde Prod. Anim., Salvador, v.16, n.3, p.746-757 jul./set.., 2015 http://www.rbspa.ufba.br ISSN 15199940

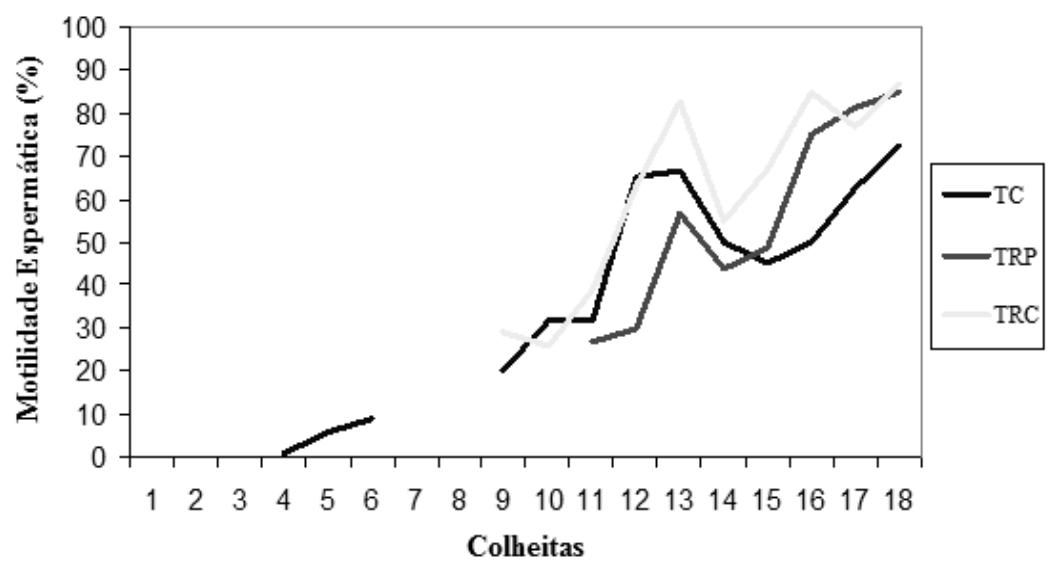

Figura 4. Motilidade espermática (\%) do ejaculado de cordeiros filhos de mães submetidas ao tratamento controle (TC), restrição energética (TRC) e proteica (TRP), durante a lactação

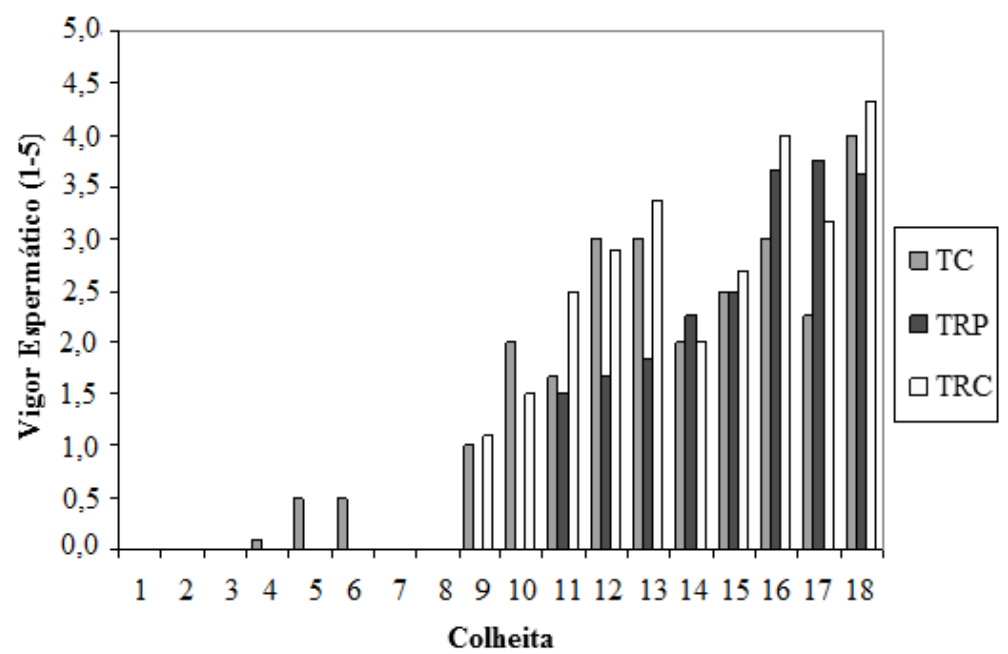

Figura 5. Vigor espermático (1-5) do ejaculado de cordeiros filhos de mães submetidas ao tratamento controle (TC), restrição energética (TRC) e proteica (TRP), durante a lactação

$\mathrm{Na}$ variável concentração espermática, também houve efeito de interação entre tratamento e ordem de colheita $(p=0,027)$, na qual TC apresentou concentração espermática acima de $50 \mathrm{x}$ $10^{6}$ espermatozóides $/ \mathrm{mL}$ na nona colheita $(75,13 \pm 129,78 \mathrm{SPTZ} / \mathrm{mL})$, com idade média de 195,42 $\pm 11,17$ dias, e o TRC obteve concentração espermática superior $(79,20 \pm 89,46 \mathrm{SPTZ} / \mathrm{mL})$ na $12^{\mathrm{a}}$ colheita, com idade média de 230,00 $\pm 7,32$ dias. $\mathrm{O}$
TRP apresentou concentração mínima $(79,16 \pm 1,75 \mathrm{SPTZ} / \mathrm{mL})$ na $16^{\mathrm{a}}$ colheita, com idade média de $292,83 \pm 8,58$ dias. Ocorrendo, então, como efeito da restrição, um maior atraso do TRP em relação ao TRC e ambos mais tardios que TC em alcançar o mínimo de $50 \times 10^{6}$ SPTZ/mL.

A idade à puberdade nos machos seria alcançada quando os animais produzissem um ejaculado com 
Rev. Bras. Saúde Prod. Anim., Salvador, v.16, n.3, p.746-757 jul./set.., $2015 \quad \underline{\text { http://www.rbspa.ufba.br }}$

concentração espermática acima de $50 \mathrm{x}$ $10^{6} \mathrm{SPTZ} / \mathrm{mL}$, com motilidade espermática pelo menos $50 \%$ e porcentagem de defeitos totais inferior a $50 \%$, em uma mesma colheita. $\mathrm{Na} 12^{\mathrm{a}}$ colheita, os tratamentos TRC e TC entraram na puberdade (idade de 230,00 $\pm 7,32$ e $236,43 \pm 11,18$ dias, respectivamente) e ambos foram mais precoces que o TRP, que, somente na $16^{\mathrm{a}}$ colheita $(292,83 \pm 8,58$ dias $)$, atingiu a puberdade, o que significa, então, um significativo atraso na idade à puberdade nos cordeiros quando suas respectivas mães sofreram restrição proteica durante a lactação, representando, em média, um atraso de 50 dias na entrada da puberdade. Alves et al. (2006) utilizaram animais da raça Santa Inês e observaram que os animais apresentaram os parâmetros que definiram a puberdade (motilidade de $10 \%$ e concentração espermática de $50 \mathrm{x}$ $10^{6} \mathrm{SPTZ} / \mathrm{mL}$ ) com uma idade à puberdade de $194,57 \pm 41,97$ dias, não sendo diferente do encontrado no TC e TRC, entretanto, deve-se levar em conta a diferença nos parâmetros para definição da puberdade entre os trabalhos. Pacheco et al. (2009) avaliaram a idade média em que carneiros da raça Santa Inês, criados no sul do Espírito Santo, alcançaram a puberdade e encontraram média de 210,8 $\pm 50,8$ dias, porém, nesse experimento, o desprendimento peniano foi o parâmetro considerado para avaliar a puberdade. A grande diversidade de parâmetros utilizados para referir-se à puberdade em cordeiros (MÉNDEZ et al., 2005) dificulta a adequada comparação com resultados de outros trabalhos.

$\mathrm{O}$ efeito de tratamento no volume do ejaculado $(p=0,0263)$, porcentagem de defeitos maiores $(p=0,0050)$ e defeitos totais $(p=0,0103)$ foi encontrado, contudo, quando os fatores foram analisados isoladamente, não foi possível detectar esta diferença (Tabela 2). Já a porcentagem de defeitos menores, o exame hipo-osmótico, e as colorações de POPE e eosina/nigrosina não obtiveram efeito de tratamento ( $>00,05)$, não sendo, então, observada influência da restrição energética ou proteica nestas avaliações seminais. Corrêa et al. (2006) não observaram diferenças $(p>0,05)$ entre os regimes alimentares diferenciados sobre as variáveis defeito maior, defeito menor e defeito total nos espermatozoides ejaculados, mas encontraram efeito no volume de sêmen, sendo, o maior efeito, obtido em touros jovens estabulados, quando comparados com animais criados a pasto com e sem suplementação.

Tabela 2. Média e desvio padrão do volume do ejaculado (VOL) e porcentagem de defeitos maiores (DM) e totais (DT) de cordeiros cujas mães foram submetidas a diferentes tratamentos - controle (TC), restrição calórica (TRC) e restrição proteica (TRP) - durante o período de lactação

\begin{tabular}{lccc}
\hline \multirow{2}{*}{ Item } & \multicolumn{3}{c}{ Tratamentos } \\
\cline { 2 - 4 } & $1,43 \pm 0,61$ & TRC & TRP \\
\hline VOL $(\mathrm{ml})$ & $16,45 \pm 12,57$ & $1,34 \pm 0,48$ & $1,48 \pm 0,71$ \\
DM & $33,14 \pm 13,01$ & $14,64 \pm 11,28$ & $12,17 \pm 9,49$ \\
DT & & $31,85 \pm 15,85$ & $28,60 \pm 15,64$ \\
\hline
\end{tabular}

$\mathrm{P}>0,05$. 
Nas fêmeas ovinas analisadas, não foi encontrado efeito de tratamento e da interação entre ordem de colheita e tratamento nutricional $(\mathrm{p}>0,05)$ sobre $\mathrm{o}$ número total de folículos, diâmetro médio folicular, total de folículos maior ou igual a $3 \mathrm{~mm}$ de diâmetro e também no total de folículo maior que $3 \mathrm{~mm}$. Esses resultados também foram encontrados por Grazul-Bilska et al. (2006), que utilizaram valores da dieta para as ovelhas acima (ad libitum) e abaixo $(60 \%)$ da mantença. Kakar et al. (2005) utilizaram dietas de 0,5, 1,0 e 1,5 da mantença, e o resultado também foi semelhante ao encontrado. Contudo, esses autores não trabalharam com animais pré-púberes e/ou púberes, sendo que Nolan et al. (1998) encontraram, em novilhas de corte tratadas com FSH e alimentadas com uma dieta de baixa energia $(9,6 \mathrm{Mcal} / \mathrm{kg}$ $\mathrm{EM} / \mathrm{d}$ ), por 17-19 dias, uma quantidade maior de folículos ovarianos que em as vacas alimentadas com uma dieta de elevada energia (28,6Mcal/kg EM/d). Verificou-se a interação significativa $(\mathrm{p}=0,0179)$ entre tratamentos e colheita sobre o aparecimento do corpo lúteo. A presença do corpo lúteo expressa a existência da fase lútea do ciclo estral, que demonstra a ocorrência de um ciclo, pois esta fase é posterior à fase folicular, na qual os folículos irão se desenvolver até um se tornar ovulatório (MARTIN \& FERREIRA, 2009), podendo-se, então, indicar a entrada, na puberdade, das fêmeas. As fêmeas do TC apresentaram corpo lúteo na $10^{\mathrm{a}}$ colheita, com uma idade média de $210,43 \pm 11,18$ dias; já o TRC, na $11^{\text {a }}$ colheita, com idade média de $216 \pm 7,32$ dias. As fêmeas do TRP apresentaram um atraso na puberdade, pois somente na $13^{\mathrm{a}}$ colheita, com uma média de $251,83 \pm 8,59$ dias de idade, apresentou corpo lúteo.
A restrição calórica e proteica imposta às mães durante a lactação alterou algumas das características espermáticas, entretanto, somente a restrição proteica das mães, durante o período os primeiros 60 dias de lactação, promoveu um atraso no início da puberdade em machos e fêmeas.

\section{REFERÊNCIAS}

AGUIAR, C.S.; SANTANA, A.F.; SOUZA, E.C.A.; LIMA, M.C.; FELIZOLA, C.A.; CRUZ, G.A.M.; FARIAS JUNIOR, N.A. Análise da correlação entre circunferência escrotal e medidas corporais de ovinos da raça Santa Inês de cinco a sete meses de idade. PUBVET, v.2, n.8, 2008.

ALVES, J.M; MCMANUS, C.; LUCCI, C.M.; CARNEIRO, H.C.R.; DALLAGO, B.S.; CADAVID, V.G.; MARSIAJ, P.A.P.; LOUVANDINI, H. Estação de nascimento e puberdade em cordeiros Santa Inês. Revista

Brasileira Zootecnia, v.35, n.3, p. 958966, 2006.

AVELLANEDA, Y.; RODRÍGUEZ, F.; GRAJALES, H.; MARTÍNEZ, R.; VASQUEZ, R. Determinación de la pubertad en corderos en el trópico alto colombiano por características corporales, calidad del eyaculado y valoración de testosterona. Livestock Research for Rural Development, v. 18, article 138, 2006.

BACINOGLU, S.; TAS, M.; CIRIT, U.; OZDAS, O.B.; AK, K. The potential fertility estimation capacity of the hypoosmotic swelling test, the thermal stress test and a modified cervical mucus penetration test in the bovine. Animal Reproduction Science, v.104, p.38-46, 2008. 
Rev. Bras. Saúde Prod. Anim., Salvador, v.16, n.3, p.746-757 jul./set.., $2015 \quad \underline{\text { http://www.rbspa.ufba.br }}$ ISSN 15199940

CARDOSO, D.; NOGUEIRA, G.P. Mecanismos neuroendócrinos envolvidos na puberdade de novilhas. Arquivos de Ciências Veterinárias e Zoologia da Unipar, v.10, n.1, p. 5967, 2007.

\section{COLÉGIO BRASILEIRO DE} REPRODUÇÃO ANIMAL - CBRA. Manual para exame andrológico e avaliação seminal. 2. ed., Belo Horizonte, 1998. 49p.

CORRÊA, A.B.;VALE FILHO, V.R.; CORRÊA, G.S.S.; ANDRADE, V.J.; SILVA, M.A.; DIAS, J.C.

Características do sêmen e maturidade sexual de touros jovens da raça Tabapuã (Bostaurusindicus) em diferentes manejos alimentares. Arquivo

Brasileiro Medicina Veterinária Zootecnia, v.58, n.5, p.823-830, 2006.

GRAZUL-BILSKA, A.T.; BOROWCZYK, E.; ARNDT, W.; EVONIUK, J.; O'NEIL, M.; BILSKI, J.J.; WEIGL, R.M.; KIRSCH, J.D.; KRAFT, K.C.; VONNAHME, K.A.; REDMER, D.A.; REYNOLDS, L.P.; CATON, J.S. Effects of overnutrition and undernutrition on in vitro fertilization (IVF) and early embryonic development in sheep. Sheep and Beef Day, v.47, p.56-66, 2006.

HULET, C.V.; SHELTON, M. Ovinos e caprinos.In: HAFEZ, E.S.E.; HAFEZ, B. Reprodução animal. $7^{\text {a }}$ ed., São Paulo: Manole, 2004. p.397-41.

JACOMINI, J.O.; ESPER, C.R.; DINIZ, E.G.; VIEIRA, R.C.; BELETTI, M.E. Morfogênese do testículo de embriões e fetos de vacas da raça nelore (Bos taurus indicus). Brazilian Journal of Veterinary Research and Animal Science, v.44, n.1, p.33-39, 2007.
KAKAR, M.A.; MADDOCKS, S.; LORIMER, M.F.; KLEEMANN, D.O.; RUDIGER, S.R.; HARTWICH, K.M.; WALKER, S.K. The effect of periconception nutrition on embryo quality in the superovulated ewe. Theriogenology, v.64, n.5, p.1090-1103. 2005.

KINDER.J.E.; DAY.M.L.; KITTOK.R.J. Endocrine regulation of puberty in cow and ewes. Journal of Reproduction and Fertility, v.34, p.167-186, 1987.

LOBATO, E. FERRO, R.A.C.; SANTOS, K.J.G.; COSTA, M.A.; FERRO, D.A.C.; SANTOS, A.P.P. Fisiologia reprodutiva de ovinos. PUBVET, v.7, n.15, 2013.

MAIA, M.S.; MEDEIROS, I.M.; LIMA, C.A. Características reprodutivas de carneiros no Nordeste do Brasil: parâmetros seminais. Revista Brasileira de Reprodução Animal, v.35, n.2, p.175-179, 2011.

MANCIO, A.B.; SANTIAGO, L.L.; GOES, R.H.T.B.; MARTINS, L.F.; CECON, P.R. Perímetro escrotal e idade à puberdade em ovinos Merino Australiano submetidos a diferentes regimes alimentares. Acta Scientiarum. Animal Sciences, v.27, p.449-457, 2005.

MARTIN, I.; FERREIRA, J.C.P. Fisiologia da ovulação e da formação do corpo lúteo bovino. Veterinária e Zootecnia, v.16, n.2, p.270-279, 2009.

MARTINS, D.R.; MCMANUS, C.; CARVALHÊDO, A.S.; BORGES, H.V.; SILVA, A.E.D.F.; SANTOS, N.R.

Avaliação da sazonalidade reprodutiva de carneiros Santa Inês criados no Distrito Federal. Revista Brasileira de Zootecnia, v.32, n.6, p.1594-1603, 2003. 
Rev. Bras. Saúde Prod. Anim., Salvador, v.16, n.3, p.746-757 jul./set.., $2015 \quad \underline{\text { http://www.rbspa.ufba.br }}$

MÉNDEZ, J.V.; QUIROGA, M.J.T.; MARTÍNEZ, M.A.E.; LEDEZMA, J.A.; VILLALOBOS, J.M.B. Pubertad en corderos pelibuey nacidos de ovejas con reproducción estacional o continua. Revista Científica, FCV-LUZ, v 15, n.5, p.437- 442, 2005.

NOLAN, R.; O'CALLAGHAN, D.; DUBY, R.T.; LONERGAN, P.; BOLAND, M.P. The influence of shortterm nutrient changes on follicle growth and embryo production following superovulation in beef heifers.

Theriogenology, v.50, p.1263-1274, 1998.

NATIONAL RESEARCH COUNCIL NRC. Nutrient Requirements of

Sheep. 6th ed. Washington, DC:

National Academy Press, 1985.

PACHECO, A.; OLIVEIRA

MANDELLA, A.F.; QUIRINO, C.R.; LANDIM, A.V. Características seminais de carneiros da raça Santa Inês na pré-puberdade, puberdade e na póspuberdade. Ars Veterinária, v.25, n.2, p.90-99, 2009.

PACHECO, A.; QUIRINO, C.R. Comportamento sexual em ovinos.

Revista Brasileira de Reprodução Animal, v.34, p.87-97, 2010.

PIRES, A.V. Aspectos nutricionais relacionados à reprodução. In:

BERCHIELLI, T.T.; PIRES, A.V.; OLIVEIRA, S.G. Nutrição de

Ruminantes. Jaboticabal: FUNEP, 2011. p.537-559.

POPE, C.E.; ZHANG, Y.Z.;

DRESSER, B.L. A simple staining method for evaluating acrossomal status of cat spermatozoa. Journal of Zoo and Wildlife Medicine, v.22, n.1, p.8795, 1991.
ROBINSON, J.J.; ASHWORTH, C.J.; ROOKE, J.A.; MITCHELL, L.M.; MCEVOY, T.G. Nutrition and fertility in ruminant livestock. Animal Feed Science and Technology, v.126,p.25976, 2006.

SARTORI, R.; ROSA, G.J.M.; WILTBANK, M.C. Ovarian Structures and Circulating Steroids in Heifers and Lactating Cows in Summer and Lactating and Dry Cows in Winter.

Journal of Dairy Science, v.85, n.11, p.2813-2822, 2002.

STATISTICAL ANALYSIS SYSTEM - SAS. The statistical analyze systems for windows. Version 8. Cary, 19992001.

Data de recebimento: 04/09/2014

Data de aprovação: 28/07/2015 